\title{
El relato de la vida de san Vicente Ferrer antes y después de Trento
}

\author{
The Narrative of the Life of Saint Vincent Ferrer \\ before and after Trent
}

\section{CARMe ARronis Llopis}

Filologia Catalana

Universitat d'Alacant

Ctra. de St Vicent del Raspeig s/n. Alacant, o369o

arronis@ua.es

Orcid ID 0000-0001-7635-0435
RECIBIDO: 24 DE JUNIO DE 2019 ACEPTADO: 13 DE AGOSTO DE 2019
Resumen: Desde el inicio de su culto se escribieron numerosas vidas de san Vicente Ferrer, y cada una de ellas destaca o afianza determinados aspectos de su polifacética santidad, especialmente en el Quinientos, cuando, por un lado, su imagen y su culto todavía están en proceso de consolidación y, por otro, asistimos a una revisión de los parámetros de la hagiografía como consecuencia de las directrices dictadas por el Concilio de Trento. El análisis de los primeros relatos sobre el santo que se elaboraron en romance en el área de Valencia (su lugar de origen, y donde, lógicamente, su devoción arraigó de manera particular) permitirá conocer tanto los avatares de determinados textos a lo largo de la centuria, como la reescritura de la vida del santo según los parámetros que dictará la ortodoxia.

Palabras clave: Vicente Ferrer. Hagiografía. Miquel Peres. Flos sanctorum. Vicente Justiniano Antist.

\begin{abstract}
Since the beginning of his cult many lives of St. Vincent Ferrer were written, and each of them highlights or strengthens certain aspects of his multifaceted sanctity, especially in the 16 th century, when, on the one hand, his image and his cult are still in process of consolidation and, on the other, there is a review of the parameters of hagiography as a result of the guidelines dictated by the Council of Trent. The analysis of the earliest stories about the saint that were elaborated in Romance in the area of Valencia (his place of origin, and where, logically, his devotion succeeded especially) will allow us to know both the avatars of certain texts throughout the century and the rewriting of the saint's life according to the parameters that orthodoxy will dictate.
\end{abstract}

Keywords: Vincent Ferrer. Hagiography. Miquel Peres. Flos sanctorum. Vicente Justiniano Antist. 
E n el Concilio de Trento la Iglesia Católica reafirmó el culto a los santos siguiendo la tradición secular arraigada entre los fieles, pero instó asimismo a la responsabilidad pastoral para el correcto adoctrinamiento en la materia. Esto suponía un mayor control sobre la devoción privada, e implicaba necesariamente la revisión de los materiales devotos empleados para el ejercicio de la fe individual.

Se intentó atajar principalmente tres aspectos problemáticos de los textos hagiográficos: el poco rigor con que algunas vidas de santos habían sido transmitidas, incluyendo motivos de procedencia apócrifa y legendaria que restaban crédito al conjunto; la presencia abundante de elementos de carácter sobrenatural, que promovía en los fieles la fascinación por lo maravilloso en detrimento de lo edificante; y la veneración excesiva que se profesaba a los santos, considerados a menudo como los artífices de prodigios, y no como intercesores de los fieles ante Dios, quien obraba la gracia. Si bien estas cuestiones ya venían siendo denunciadas por los principales teólogos ortodoxos durante la primera mitad del Quinientos, los severos ataques a la materia de los detractores luteranos apremiaron la revisión de los escritos. ${ }^{1}$

Tanto los grandes legendarios hagiográficos medievales como los relatos exentos de vidas de santos pronto fueron sometidos a examen; urgía una adecuación de los relatos a los nuevos criterios de santidad para que, por un lado, cumplieran con el rigor que exigía la Historia de la Iglesia, y, por otro, ponderaran los dogmas identitarios católicos en contraposición con los de los protestantes. Y si bien fueron relativamente pocos los textos hagiográficos vetados o purgados por los órganos censores, ${ }^{2}$ fue mucho más habitual que nuevos textos afines al espíritu postridentino fueran sustituyendo progresivamente los materiales anteriores de origen medieval.

Desde esta óptica, y partiendo de las premisas referidas, propongo analizar las transformaciones que experimentó un caso concreto, el del relato hagiográfico del dominico san Vicente Ferrer (1350-1419), uno de los santos más populares y venerados en el contexto hispánico anterior y posterior a Trento. Y no solo me refiero a los avatares de determinados textos concretos, sino a la evolución del discurso que se forjó sobre el santo dominico antes y después de las conclusiones del Concilio. Así pues, planteo un breve recorri-

1. Sobre la controversia del culto a los santos entre hagiógrafos católicos y protestantes, ver Baños.

2. Arronis (2018 y 2019) y Albisson analizan las razones que pudieron motivar la prohibición de relatos hagiográficos en los Índices de censura hispánicos. 
do por los principales textos producidos en romance desde finales del siglo XV y a lo largo del siglo XVI en el contexto valenciano, área de particular devoción por el santo. Me referiré principalmente a la vida breve en catalán que recoge el Flos sanctorum romançat, que se editó en distintas ocasiones entre 1490-96 y 1575, a la valenciana Vida de sant Vicent Ferrer de Miquel Peres (1510), que se tradujo y editó en castellano en 1589 , y a la Vida y bistoria del apostólico predicador sant Vincente Ferrer (1575) de Vicente Justiniano Antist, aunque aludiré también a otros textos posteriores, como las compilaciones postridentinas que sustituyeron a los santorales medievales, que aunque ya no se editaron en Valencia, sí tuvieron allí difusión.

El caso de la hagiografía de san Vicente resulta interesante por varios motivos. En primer lugar, dado que su canonización data de 1455, en el periodo que me propongo analizar la imagen de su santidad todavía se encuentra en proceso de consolidación, lo que permite que sea fácilmente modelada -o, al menos, más fácilmente- por el autor de cada relato según los intereses espirituales que persigue, de manera que se resaltan unos u otros aspectos de su polifacética santidad. ${ }^{3}$

En segundo lugar, el hecho de que se trate de un santo bajomedieval también conlleva una serie de consideraciones que, en principio, apuntarían a la menor aparición de elementos inconvenientes en las narraciones de su vida, en comparación con las de otros santos más antiguos, a priori más deturpadas por la mera difusión del relato a través de los siglos. Además, Vicente Ferrer ya encarna el nuevo ideal de santidad bajomedieval, un modelo ejemplar piadoso, de vida ascética a imitación de Jesucristo, el que para André Vauchez (269) es el paradigma más representativo de la santidad bajomedieval en el área mediterránea, distinto del modelo de santo martirizado característico de los primeros siglos del cristianismo. Asimismo, su canonización ya se llevó a cabo bajo unos nuevos parámetros eclesiásticos, alejados del procedimiento típicamente medieval, por lo que se observa un mayor control de la curia en el procedimiento, y un distanciamiento de la concepción popular de santidad (Vauchez 6-7). Para la canonización de san Vicente se realizaron diversos procesos, y precisamente de esas actas es de donde arrancan -de manera directa o indirecta- las narraciones más difundidas sobre su biografía. Así sucede con la que

3. Estudios como los de Smoller y Calvé sobre las primeras manifestaciones artísticas del dominico valenciano corroboran que a lo largo del siglo XV y principios del XVI la percepción de la santidad del predicador todavía se halla en construcción. 
podríamos considerar la primera Vida oficial del santo, que escribió el dominico Pietro Ranzano (1455-1456), ${ }^{4}$ con la síntesis que de esta hizo Antonino de Florencia en el III volumen de su Chronicon (1455-1458), ${ }^{5}$ o con la versión abreviada que preparó Francesco de Castiglione (1470), ${ }^{6}$ entre otros casos. ${ }^{7}$

A la vista de lo anterior, podríamos pensar que los aspectos problemáticos más habituales de las hagiografías medievales, como por ejemplo el modelo de santidad que representa el dominico, el problema de la falta de autoría reconocida de las fuentes o de historicidad de los acontecimientos narrados, quedarían resueltos, y que, por lo tanto, no cabría esperar grandes cambios o transformaciones entre las reediciones de un mismo texto, o entre los relatos anteriores o posteriores al Concilio de Trento. Aun así, sí que observaremos diferencias, en la mayoría de casos como consecuencia de la actuación de los hagiógrafos para adecuarse a los objetivos que perseguían, que hace que destaquen unos u otros aspectos de la vida del santo, y apliquen o no determinadas cautelas a la hora de construir su relato hagiográfico.

\section{EL FLOS SANCTORUM ROMANÇAT}

Probablemente, la breve noticia sobre la vida de san Vicente que incluye el incunable conocido como Flos sanctorum romançat $(1490-1496)^{8}$ es el primer relato del santo que se escribió en lengua catalana (Ferrando 103) y el primero en romance en la Península. Era habitual que los flores sanctorum, las traduc-

4. La narración de Ranzano aúna el esquema estructural consolidado por el género hagiográfico, los rasgos de la santidad dominica, forjada sobre el modelo de santo Domingo de Guzmán, con los testimonios emotivos de los testigos coetáneos (Robles, xviii), aspectos que apuntalarán las biografías posteriores sobre el valenciano.

5. Esta vida breve tuvo una gran difusión en el área de Valencia, debido a los estrechos lazos de la orden dominica a ambas orillas del Mediterráneo, y, tal vez por su mayor brevedad, constituirá la base principal de muchas otras vidas, en concreto de dos de los abordados aquí, la que contiene el Flos sanctorum, y la de Miquel Peres, según veremos.

6. Esta última (Venecia, 1496), según declaraba el propio el autor, pretendía principalmente remover la piedad de los fieles, por lo que favorece la inclusión de episodios sobrenaturales, lo que será severamente criticado por hagiógrafos posteriores (Robles, xviii).

7. Ver en Smoller (169) una cronología de los relatos hagiográficos tempranos sobre el santo valenciano.

8. Solo uno de los dos incunables catalanes del Flos sanctorum romançat incluye la vida de san Vicente Ferrer. Se trata de I2, ff. LXXXVIc-LXXXVIIb (ver edición en Càmara 1123-25), y a pesar de que a menudo aparezca citado con fecha de 1496, el único ejemplar conservado en la Biblioteca del Seminario Episcopal de Barcelona (inc. 58) no contiene colofón. Las diferentes dataciones que le han atribuido los bibliófilos hacen que Hèctor Càmara (46), editor del volumen, proponga el intervalo 1490-1496. Las reediciones posteriores del santoral catalán se llevaron a cabo a partir de este incunable, y por tanto, siempre incluyeron la vida del dominico. 
ciones al vernáculo de la Legenda Aurea de Jacobo de la Vorágine, incluyeran algunos capítulos nuevos que aumentaban el grueso de la compilación original. Normalmente las nuevas vidas añadidas se hacían eco de las devociones locales, por lo que la inclusión de la vida del dominico valenciano no sorprende lo más mínimo. ${ }^{9}$ Las otras hagiografías añadidas al Flos sanctorum romançat se ocupan bien de mártires de los primeros siglos de la zona catalanohablante, como por ejemplo san Narciso y san Félix de Gerona, santa Eulalia, san Cucufate y santa Columba de Barcelona, santa Susana de Tarragona, etc., o bien de santos posteriores o coetáneos a Vorágine, como santa Clara, santa Catalina de Siena o san Bernardino, a los que se profesaba gran devoción por ser adalides de las principales órdenes mendicantes (Càmara 48-49). ${ }^{10}$ En el caso de san Vicente concurrían ambas circunstancias.

La noticia que se recoge sobre Ferrer es breve; es, de hecho, una versión muy resumida del relato De sancto Vincentio confessore que san Antonino de Florencia incluyó en la Pars III de su Chronicon, ${ }^{11}$ aunque en ningún punto se cita ni declara la fuente, tal y como era habitual en las compilaciones hagiográficas medievales. Como ya concluyó Laura Smoller (177), Antonino, también dominico, pretendía presentar al valenciano como un modelo paradigmático de la observancia dominica y de la misión de predicación de la orden, en el que confluían además la gracia y favor divinos: "Antoninus also made abundant use of canonization inquests and other sources to append to his life an extensive list of prophecies and miracles, both in vita and worked after Vincent's death" (178). De hecho, lo presenta casi como un nuevo apóstol, "distinguished in virtues, deeds, and miracles" (179), y la narración de los hechos prodigiosos supera con creces el espacio que dedica a la biografía.

Smoller, en su estudio de las manifestaciones literarias y artísticas producidas en la centuria posterior a la canonización de san Vicente -aunque no se

9. En cambio, los flores sanctorum castellanos no recogieron una versión de la vida del valenciano hasta el siglo XVI. Solo las ediciones de la compilación A, el conocido como Flos sanctourm renacentista (1516, Zaragoza, Jorge Cocci, y reediciones posteriores), incorporaban la vida del dominico en una versión diferente de la compilación catalana (sobre la tradición editorial de este santoral, ver Aragüés 353-55). Previamente, solo el manuscrito escurialense m.II.6, del siglo XV, revela cierto interés por el dominico al añadir a la compilación hagiográfica el Sermón de la pasión de Fhesu Christo que predicó frey Viçente [Ferrer] en Murcia, junto a una Contemplación de la Pasión en castellano.

10. Completan la nómina de vidas añadidas las relativas a devociones arraigadas en la zona desde antiguo, pese a no tener vinculación geográfica alguna, como es el caso de san Roque, santa Tecla, san Onofre o san Ponce (Càmara 52).

11. Ver la edición del texto en Ferrando (89-103). 
ocupa del texto que ahora tratamos-, concluye que el aspecto taumatúrgico del dominico, ejemplificado en la mayoría de los relatos a través del milagro de la resurrección del niño cocinado por su madre, es uno de los más representativos del santo ya en esta fase temprana de su culto. Para Smoller, incluso en las vidas más breves sobre el santo que se añadieron a las grandes compilaciones hagiográficas medievales, "authors found irresistible the tale that Ranzano had made Vincent's signature miracle: the story of the chopped-up baby" (190). Estas conclusiones de Smoller se basan en el análisis de los primeros relatos latinos añadidos a las grandes compilaciones medievales. En concreto hace referencia a dos ediciones ampliadas de la Legenda Aurea: la Historic plurimorum sanctorum o Legenda aurea sanctorum (Colonia: Ulrich Celo, 1483) y la Legenda vt vocant, seu Sanctorum Sanctarumque vite de 1554 (Lyon: Godefridum Gailliandum); ${ }^{12}$ y a otras dos compilaciones hagiográficas que la incluyen: la de Johannes Meyer (1466), el Liber de illustribus viris ordinis praedicatorum, y la de Petrus de Natalibus, Catalogus Sanctorum et gestorum eorum (Lyon: Jacques Sacon, 1519). Efectivamente, en todas estas vidas se relata dicho milagro siguiendo la versión de Ranzano. ${ }^{13}$

Teniendo en cuenta estas premisas, choca que, en cambio, la temprana vida "De sanct Vicens Ferrer" del Flos sanctorum romançat que ahora analizamos haya desterrado casi totalmente esta faceta del santo y se limite a afirmar, tras su muerte en Vannes: "En lo qual loc ha fets e fa molts miracles a honor e glòria de Déu omnipotent" (Càmara 1125). En el relato ni se recoge el popular milagro del niño resucitado ni ningún otro. En realidad, no se narra ningún suceso de carácter sobrenatural. La vida se limita a presentar brevemente la ascendencia familiar del valenciano, su ingreso en la orden a los dieciocho años, para pasar a describir con más detalle su tarea pastoral y su vida ascética y penitente. Este proceder del autor sorprende si consideramos tanto la tendencia de las otras manifestaciones tempranas, ${ }^{14}$ como el hecho de que la fuente de la que parte dedica una gran atención a los milagros obrados por el san-

12. Smoller (192) se refiere a una edición de esta compilación de 1555, pero la de 1554 que cito ya contiene la vida del santo.

13. Sin embargo, una de las primeras noticias que se escribieron del santo, la contenida en el Formicarius, del dominico teutón Johannes Nider (ca. 1437), destacaba exclusivamente su faceta como predicador ejemplar (Calvé 321).

14. A las citadas por Smoller, podríamos añadir el relato que el Flos sanctorum renacentista castellano incorpora en 1516, que sí incluye muchos de los milagros recogidos por Antonino (una de las fuentes que parece seguir) y demás acontecimientos sobrenaturales, como su don profético o la aparición de Jesucristo mientras está convaleciente. 
to. El anónimo compilador, por lo tanto, renuncia deliberadamente a desarrollar la faceta taumatúrgica del dominico valenciano y su don profético, y muestra una intención y un propósito distinto al del resto de hagiógrafos coetáneos. Del Chronicon de san Antonino exclusivamente selecciona aquellos fragmentos que le interesan $-\mathrm{y}$ los traduce con fidelidad- para presentar al santo como un predicador ejemplar de vida ascética y para describir la efectividad de sus sermones comparándolos con los de los apóstoles:

Hagué special gràcia de Déu en lo seu sermonar, que era no poca abmiració, axí com los apòstols, que en qualsevulla part que sermonàs y en la lengua sua materna era entés per altres nacions. E, encara que los seus sermons fossen prolixos, negun dels oïdors no s'enujava, car la sua loqüela fervent e devota scalfava los ànimos dels oïnts com a falla. Era axí mateix per special do de l'Sperit Sant oït tant per los qui luny li eren com per los qui prop li staven, tant per indoctes com per doctes, tant per innobles com per nobles, tant a moros com a jueus [...] (Càmara 1123-24)

$\mathrm{Al}$ tratar de su predicación tampoco hace referencia alguna al anuncio de la inminente llegada del Anticristo y del Juicio Final, uno de los principales tópicos de sus sermones, del que también solían hacerse eco las hagiografías breves (Smoller 190-91). Solo coincide con el resto de relatos en el hecho de aludir mínimamente a su participación en el Cisma a favor del papa de Aviñón, y a su posterior cambio de parecer: "fon ab molta familiaritat ab lo dit papa Benet, del qual aprés se apartà per certs bons respectes” (Càmara 1124).

Esta breve noticia, por tanto, subraya casi exclusivamente su efectiva labor pastoral y su modelo de vida ascética extrema. En la orden dominica, de manera particular, existía la tradición de reunir relaciones de hombres ilustres de la congregación, que sirvieran para reflejar la identidad colectiva y estimular el ejemplo en la comunidad (Huijbers 298). Parece evidente que ese es el principal objetivo del anónimo autor -probablemente dominico-. Otra de las hipótesis que podríamos plantear es si el compilador ya mostraba ciertas cautelas sobre la inclusión de milagros en los relatos que distrajeran la atención de los fieles del verdadero carácter ejemplar que se pretendía subrayar, y que por eso decidiera no narrarlos y solo referirse a ellos de manera somera.

Sea como fuere, este relato continuó imprimiéndose idéntico en las posteriores ediciones del flos sanctorum catalán a lo largo del Quinientos: en la valenciana de 1514, de Jorge Costilla, y en las barcelonesas del taller de Carles Amorós de 1519-1520, de 1524 y de 1547, e incluso en la barcelonesa de 1575, 
ya postridentina, impresa en el taller de Jaume Cendrat y la viuda de Monpasada. En esta última, la vida se acompaña de un grabado más tosco que imita el de las ediciones anteriores.

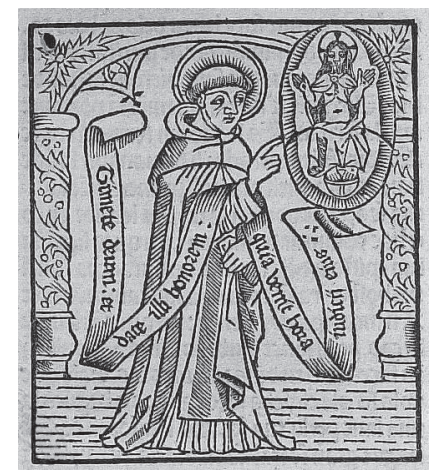

Flos sanctorum romançat (1490-1496, f. 81v)

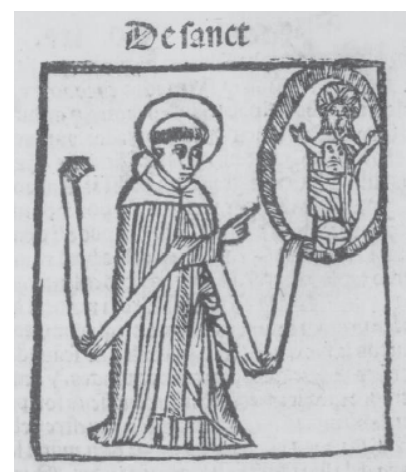

Flor dels Sants $(1575$, f. 65v)

Esta última edición del volumen, publicada (como la de 1547) con el título de Flor dels sants, incluye un interesante prólogo "ad pium lectorem" en clara sintonía con la sensibilidad postridentina. El anónimo autor de este proemio expone un alegato sobre la utilidad de la lectura de las vidas de los santos, ya que "mostren los modos y medis condignes com havem de alcançar aquella eterna glòria de Paradís", tras recordar que la salvación se consigue exclusivamente a través de la práctica de "les virtuts e bones obres" y el cumplimiento de los mandamientos, afirmaciones que se alinean con el posicionamiento de la Iglesia católica en la controversia de la justificación por la fe mantenida con los protestantes, zanjada para los católicos en la sesión VI de 13 de enero de 1547 del Concilio de Trento.

Es evidente que el relato sobre san Vicente que incluía el Flos santorum romançat no resultaba problemático a ojos de los censores, por lo que siguió editándose hasta que esta compilación catalana de origen medieval fue remplazada en el mercado por los nuevos santorales de Alonso de Villegas y Pedro Ribadeneira. ${ }^{15}$ Se dio, por tanto, durante décadas, la siguiente situación paradójica: mientras crecía la devoción local por el santo y proliferaban las re-

15. Villegas incluye la vida de Ferrer en el primer tomo de su santoral (Toledo: Viuda de Juan Rodríguez 1591 [1588]), en el tercer y último bloque dedicado a "las Fiestas y Santos de España" (46v-48v), y Ribadeneira, en el tercer volumen, el dedicado a las Vidas de santos que comúnmente llaman extravagantes (Madrid: Luis Sánchez 1604, 93-110). 
laciones de milagros impresas -como veremos-, el Flos sanctorum catalán ofrecía a los fieles únicamente la noticia de su vida ejemplar, sin explayarse en su conocida faceta taumatúrgica -quién sabe si quizá, precisamente, para contrarrestar ese fervor-.

De hecho, los nuevos santorales que reportan la vida del valenciano también son moderadas en la inclusión de lo sobrenatural, especialmente el relato de Villegas, que no narra ninguno de sus milagros. Parece que ambos autores quieren destacar casi en exclusiva su vida ejemplar desde todos los aspectos, pero sin recurrir en demasía a su faceta sobrenatural, como ya había hecho el anónimo compilador catalán. Sin embargo el jesuita Ribadeneira, pese a que su santoral, en líneas generales, demuestra ser mucho más comedido en el gusto por lo maravilloso que el de Villegas, no escapa a la fascinación de subrayar la abundancia de sus prodigios e incluso de relatar el del niño cocinado, aunque, como declara, no es esa la intención que persigue: "Y siendo tantos los milagros, sería cosa larga, y fuera de mi propósito, quererlos aquí referir; uno solo escreviré yo, por ser tan raro y muy extraordinario, de un niño que resucitó medio crudo y medio cozido, y fue desta manera" (Ribadeneira 101).

Pero si bien las nuevas compilaciones modernas obedecieron sobre todo a la intención de demostrar que el santo lo es por su vida, y no por sus prodigios, no conviene generalizar ni atribuir este comportamiento a todos los hagiógrafos postridentinos. También encontraremos a reputadas figuras de la Iglesia y de la orden dominica fascinadas principalmente por la faceta taumatúrgica de Vicente Ferrer, como será el caso del dominico Andrés Ferrer de Valdecebro, calificador del Consejo de la Suprema Inquisición, que en su Historia de la vida maravillosa y admirable del segundo Pablo apóstol de Valencia, san Vicente Ferrer (Madrid: Mateo de Llanos, 1682) ${ }^{16}$ declarará en el preámbulo "Al que leyere" la necesidad de escribir un nuevo relato sobre san Vicente alegando que los que ya existen no recogen la totalidad de sus prodigios. De hecho, sobre la vida de Antist de la que me ocupo más adelante, concluye que no contiene todo lo prodigioso probablemente a causa de que la documentación que este manejó de la canonización estaba afectada de polilla: "sin poderse leer un renglón entero, y adonde debían estar las cosas de mayor prodigio, que después se han ido revelando [...] que no merecían estar entregadas al olvido". Sin embargo, intenta maquillar esa fascinación recogiendo una reflexión sobre la conveniencia de escribir la vida del dominico sin sus milagros:

16. La cuarta edición de la obra, de 1729, se imprimió en Valencia. 
Me dixo el excelentísimo señor Conde de Oropesa [...] que escriviesse la vida del santo sin los milagros, y discurrió con gran peso de juizio, porque la vida es para imitar, los milagros para admirar, y de la admiración no se saca ningún provecho, de la imitación muchos. Y los santos mayor gloria accidental reciben de que se sigan sus virtudes, que no de que se assombren sus milagros. (Ferrer de Valdecebro, del preámbulo "Al que leyere", s. p.)

Cuestión que zanja en su texto separando en "libros" distintos el relato de la biografía de la extensa narración de los milagros. ${ }^{17}$ No es posible, pues, establecer conclusiones generales sobre el proceder de los hagiógrafos anteriores y posteriores a Trento con relación a lo prodigioso; resulta mucho más atinado analizar los objetivos de cada autor caso por caso.

\section{LA VIDA DE SANT ViceNT FerReR DE Miquel PeReS}

La primera narración exenta aparecida sobre el santo en Valencia (Joan Jofré, 1510) es La vida de sant Vicent Ferrer de Miquel Peres, célebre autor y traductor de obras hagiográficas y devotas, entre otras, una Vida de la también dominica Catherina de Sena (Valencia: Cristóbal Cofman, 1499). ${ }^{18}$ Tradicionalmente sus obras han sido consideradas meras traducciones, aunque embellecidas en lo retórico con la artificiosidad de la prosa, acorde al gusto de la época; en consecuencia, han sido poco estudiadas desde el punto de vista creativo, o desde la espiritualidad intimista en la que hay que entender su producción. Y es que todos los libros de Peres pretenden ser materiales devotos de uso privado para la práctica de la devoción contemplativa, afín a la sensibilidad franciscana, y están dirigidas a un público laico que anhela la edificación individual.

Como ya demostró Curt Wittlin, Peres se basó en las principales fuentes italianas que reportaban la vida del santo: las vidas de Pietro Ranzano, Anto-

17. Esta fascinación por lo prodigioso que muestra Valdecebro, y que revela una excesiva credulidad de los milagros atribuidos popularmente al santo, ya fue criticada por hagiógrafos vicentinos posteriores, como Francisco Vidal y Micó, que rebatió algunos de ellos en su Historia de la portentosa vida y milagros del valenciano apóstol de Europa san Vicente Ferrer (Valencia: Estevan Dolz 1735), probando que algunos eran "apócrifos" y otros, "fabulosos" (Robles, xxviii).

18. A estas, cabe añadir una traducción muy libre de la Imitatio Christi (1482) y la que fue la más popular y difundida de sus obras, la Vida de la sacratíssima Verge Maria (1494). Sobre la producción de este autor, ver los estudios y las ediciones de Arronis (2015) y Ferrando. Sobre la Vida de san Vicente que ahora nos ocupa son especialmente relevantes los estudios de Wittlin y Ferrando, que edita además el texto (153-80). 
nino de Florencia y Francesco de Castiglione, aunque, como era habitual en la tradición medieval, no sintió la necesidad de declararlas, y en la dedicatoria que precede al texto se limitó a afirmar que traducía "de latí en valenciana lengua los maravellosos actes que d'aquest gloriós sant alguns famosos doctors reciten" (Ferrando 155). Pero el texto no es solo una síntesis de materiales previos: a partir de esas vidas oficiales, articula un relato nuevo en el que ofrece una visión muy personal del dominico, presentado como un santo atemporal, del que destaca de manera particular la faceta devota y contemplativa que le atribuye.

Si bien tiene presente el modelo narrativo medieval de relato hagiográfico, que suele reproducir el esquema de "vida y milagros", su objetivo excede a esta estructura y rebasa esos límites al dedicar varios capítulos a recrear supuestas oraciones del santo. La mayoría de ellas son fruto de su pluma, aunque, como veremos, también incluye una curiosa oración contra la peste que debía de circular en la época. Por lo tanto, la vida de Peres no es solo una narración ejemplar, es a la vez un manual de edificación intimista de marcada espiritualidad contemplativa, y un producto literario de ambición estética.

El libro se divide en doce apartados o capítulos. Los primeros narran los hechos principales de su vida, describiéndola en todo punto como ejemplar, desde el nacimiento, rodeado de signos maravillosos, su modélica niñez y mocedad y su vida ascética de predicador itinerante. Como prueba de esta vida modélica, los siguientes capítulos abordan las primeras evidencias que confirman su santidad, ya en vida y tras su muerte: su don profético; la aparición en que Jesucristo le toca la mejilla cuando está convaleciente, que pone de manifiesto su comunión con él; los milagros que realizó en vida; su muerte en olor de santidad; y los milagros que obró post mortem.

Los apartados que articulan la estricta hagiografía del dominico son los más próximos a las fuentes y, aun así, también encontramos divergencias significativas. Peres decide omitir conscientemente cualquier referencia a la faceta histórica y pública del personaje. No incluye ninguna alusión al papado de Aviñón, ni a otros hechos históricos, como el compromiso de Caspe o el Concilio de Constanza. Ni siquiera reproduce nombres propios de personajes destacados a los que se refiere, prefiriendo denominaciones genéricas como el "rei d'Aragó", ni recrea el itinerario cronológico o geográfico de su vida. ${ }^{19}$

19. En cambio, en los milagros que incluye, que proceden de los relatos de Antonino y Castiglione (Ferrando 118-20), aplica un criterio distinto, y sí reproduce las localizaciones de los prodigios o los nombres propios (si constaban en la fuente manejada) para preservar la historicidad que se suponía en este tipo de sucesos. 
Incluso el episodio de la aparición de Jesucristo en que le toca la mejilla para sanarlo de una enfermedad se narra desprovisto de la significación que tuvo en la vida del santo, ya que, según recogen los relatos oficiales, marcó el inicio de su misión profética y de mensaje apocalíptico y el abandono de la corte papal. Miquel Peres quiere construir la figura de un santo atemporal, del que quiere sobre todo destacar su modelo de espiritualidad, o mejor, el modelo de espiritualidad que le atribuye.

Así, Peres, se distancia de las fuentes y presenta al predicador valenciano no solo como un ejemplo de vida ascética, marcada por la pobreza, el ayuno, la vigilia, la penitencia, etc., sino también como un paradigma de cristiano que anhela el recogimiento, dedicado a la lectura de las Escrituras y a la contemplación de la Pasión de Cristo, es decir, como un modelo ejemplar tanto en la vida como en la espiritualidad. Y si bien en las vidas oficiales se infiere este comportamiento, se subrayan mucho más otras de sus facetas. De esta manera, en el texto, si bien encontraremos referencias al santo con la terminología hagiográfica típicamente medieval, como un "sforçat cavaller" o "un cavaller celestial" de las cohortes de Dios, que se enfrenta a los enemigos del cristiano, el demonio, el mundo y la carne; también, y con mayor frecuencia, se nos presentará apartado del mundo, "retret en la sua cetla com a pàsser solitari", y en actitud contemplativa, deseando "muntar en lo traginat de contemplació devota". Y son numerosas las ocasiones en que se alude a este recogimiento:

acustumava lo excelç y digne sant cascuna nit [...] en la cruel mort y passió del redemptor Jhesús devotament contemplava. Stant una nit en aquesta alta y devota contemplació aquest contemplatiu sant. (Ferrando 159)

aprés de hun poch dormir, en alta contemplació la sua devota pensa alçava; [...]. Acabades tan santes hores, lo companyó a dormir se posava, y aquest contemplatiu sant passejava per los alegres prats y jardins de excelsa contemplació. (Ferrando 161)

Sin embargo, el libro incluye otros apartados, que equivalen a más de un tercio de la obra, a los que ya Antoni Ferrando (116) se refirió como los más originales del relato, inspirados probablemente en los sermones del santo y en tradiciones locales: "La oració que ordenà lo gloriós sant que diguessen cascun dia los qui.l seguien"; "Com aquest gloriós sant, essent en una terra que morien de pestilència, donà una oració als qui.l seguien"; "Com aquest gloriós sant, sabent que havia de morir, féu una profitosa y devota exortació a les per- 
sones que.l seguien"; "La oració que dix aquest benaventurat sant quant combregà essent malalt"; "Les paraules que dix lo gloriós sant quant se moria".

Efectivamente estos capítulos (VI, IX, X y XI) ${ }^{20}$ son recreaciones de Peres en las que pone en boca del santo valenciano parlamentos y oraciones que edifican a los fieles. El autor se demuestra un buen conocedor de los escritos de Vicente Ferrer, como se aprecia sobre todo en el apartado noveno, en que el dominico instruye a sus fieles seguidores; en él Peres sintetiza y glosa muchas de las enseñanzas del santo, aunque en un estilo muy diferente del que solía emplear el predicador en sus sermones y escritos: ${ }^{21}$

Teniu contínuament en la memòria la cruel mort y passió del nostre redemptor Jesús. [...] No ligau libres de fengides poesies, de inútils històries, ni de combats ni batalles, mas libres de la Sagrada Scriptura, on veritat se troba, y libres que lo vostre fret y gelat cor a fervent devoció enceng[u]en y de mals pensaments vos aparten. [...] Recordar deveu ab studiosa advertència les cruels y eternes penes que los miserables damnats en la trista presó d'infern eternament sentir speren, perquè, aterrats y spantats de caure en aquelles infernals flames, dexeu les males y perverses obres. [...] Fugiu com de pestilència de star ociosos, que l'oci és la porta falsa per on l'enemich dimoni a tots los peccats y vicis dóna segura entrada. (Ferrando 171-72)

Resulta llamativa la libertad con que Peres pone en boca del predicador esta serie de plegarias edificantes que ofrece a los fieles para que oren en privado, con las que sigue perfilando la espiritualidad contemplativa que le supone al santo, al tiempo que la fomenta en sus lectores, sirviéndose de la devoción que profesan por él. Son oraciones concebidas para leerlas diariamente (cap. VI), antes de recibir la comunión (cap. X), o, siguiendo los modelos de las artes moriendi medievales, para prepararse para la muerte (cap. XI), como vemos a continuación:

Senyor, Déu omnipotent e incomprensible, creador de totes les creatures, [...]. Aquesta gloriosa benaventura [...] suplique, que per les liberals

20. El original no numera los capítulos, pero sí los editores y estudiosos del texto para facilitar su consulta y análisis.

21. Recordemos que a finales del siglo XV los sermones de Vicente Ferrer ya contaban con diversas ediciones, la más antigua de las cuales es la conocida como Sermones "de tempore et de sanctis", impresos en Colonia por Heinrich Quentell en 1485. Tal vez Miquel Peres pudo conocer la edición de los sermones impresa en Venecia en 1496, que incluía al inicio la Vita sanctiii Vincentii confesoris de Francesco de Castiglione, que también usó entre sus fuentes. 
mans de vostra infinida misericòrdia me sia donada; y no la demane, Senyor, que yo per les mies obres la merexca, mas que per los mèrits de la vostra santíssima passió y per la granea de la vostra pietat y clemència me sia atorgada; [...] feu-me participar de la visió de la vostra divina essència, en la qual los meus sentiments sens fi delitar se puguen, que en la gloriosa contemplació de la vostra immensa divinitat los sentiments spirituals sentran incomparable glòria. (Ferrando 175)

Además de estas oraciones imaginadas por Peres y redactadas en la prosa cultista y artificiosa de moda en la época, incluye también una breve plegaria para guardarse de la peste (cap. VII) de características bien distintas. En ella se invoca a Jesucristo, la Virgen y a determinados santos consideradores protectores para que salven al fiel del contagio y de la muerte súbita. Se trascribe en riguroso latín, probablemente porque, a diferencia de las anteriores a las que me he referido, imaginadas por Peres, esta se debía considerar que verdaderamente procedía de alguna intervención del santo, ${ }^{22}$ por lo que su carácter preventivo residía en la inalterabilidad de la fórmula, en la repetición idéntica de las palabras tal y como el santo las habría pronunciado. ${ }^{23}$ Poco se ha ahondado en este añadido, que excede al propósito del conjunto de la obra y que obedece a un anhelo visiblemente diferente. ${ }^{24}$

Ya a finales del siglo XV se había consolidado la fama de Vicente Ferrer como santo protector contra la peste. Esta nueva faceta del dominico en el imaginario colectivo se asienta principalmente en el proceso de canonización bretón (1453-1454) en el que el 47 \% de las curaciones estaban relacionadas con el morbo (Calvé 312). Conviene recordar que, poco antes de la publicación de la obra, entre 1508 y 1510, hubo en Valencia un brote de peste particularmente virulento (Eiras 45), que sin duda acrecentó en los fieles el afán de proveerse de todo tipo de precauciones, incluidas las devotas y/o supersticiosas. Desconocemos el origen concreto de esta oración; probablemente debía de circular suelta, junto al grabado de la cruz de "set poms" que acompaña a

22. No es un caso excepcional; sabemos de otras oraciones atribuidas popularmente al santo que acabaron siendo reconocidas como auténticas en las biografías posteriores, legitimando así una tradición devota que estimaban cierta. Ver el caso de los Goigs a la Mare de Déu del Roser, escritos probablemente a finales del siglo XV, pero asumidos como vicentinos en las vidas de Francisco Vidal y Micó y Tomás Mérita, ya del Setecientos (Martínez 2018, 144-54).

23. Sobre los usos supersticiosos de las oraciones en el siglo XVI, ver los trabajos de Pérez y Londoño.

24. Sobre esta oración contra la pestilencia, ver Arronis (en prensa). 
la plegaria, por lo que Peres decidió incluir este material como uno más de los prodigios atribuidos al santo -de hecho, precede al capítulo de sus milagros en vida-, y se limitó a narrar un breve introito para darle cabida en el relato. ${ }^{25}$ En ese párrafo, tras un pequeño diálogo entre Ferrer y sus discípulos sobre el peligro de la epidemia, el santo declara que les proporcionará una oración para protegerles, y unas instrucciones sobre cómo utilizarla para ser salvos:

"[...] yo us donaré una breu oració ab una creu de set poms, que los qui ab devoció la portaran seran segurs de pestilència, fent-vos cascun matí com vos levareu, lo senyal de la creu per totes les parts del cos on se acustumen de fer les vèrtoles, dient: Jesús, Verge Maria”. E axí los donà aquesta davall scrita oració, que tots los qui ab devoció la digueren y portaren aquella terrible pestilència no.ls pogué noure. (Ferrando 165)

Este tipo de oraciones protectoras de origen incierto fueron muy comunes a finales del siglo XV y a lo largo del siglo XVI; a menudo eran usadas de manera supersticiosa, recitadas como ensalmos, o colgadas al cuello, como nóminas (Pérez). De hecho, si fueron una de las prácticas de la piedad popular más perseguidas por el Santo Oficio no fue tanto por su contenido estricto, sino por los usos que de ellas se hacía, a menudo explicitado en las rúbricas u otros paratextos accesorios -como en este caso-, de manera que excedían lo devoto para incurrir en lo mágico (Londoño). Y no deja de ser paradójico leer cómo en este texto es precisamente san Vicente en primera persona el que describe estos usos poco ortodoxos de la oración, como por ejemplo, estar protegido solo por llevar consigo la oración ("los qui ab devoció la portaran”), o por persignarse en distintas partes del cuerpo. Pero el control de estas prácticas no se intensificó hasta avanzada la centuria, por lo que tampoco ha de sorprendernos este añadido de Peres, pues no apreciaría inconveniente alguno, al contrario, lo estimó un material provechoso para ser difundido entre los devotos del santo.

Por todo lo expuesto, el texto de Peres se demuestra más complejo y singular de lo que podría parecer a simple vista. Revela la gran libertad creativa

25. Sanchis Sivera, en la Historia de san Vicente Ferrer que preparó a principios del siglo Xx, contextualiza el origen de esta oración en un episodio histórico más concreto; la habría pronunciado en la Torre de Ramón de Esplà, cerca de Barcelona: "Predicando un día en la residencia real [...] y en presencia de Benedicto XIII y de otros muchos nobles, publicó desde el púlpito una oración que había compuesto, y que recomendó al concurso que le oía, para librarse de la muerte y alcanzar buena muerte" (Sanchis Sivera 223). Sin embargo, Arronis (en prensa) aclara que esta afirmación de Sanchis se produce por una interpretación errónea de los materiales aportados por Fagés. 
con que el autor se ha servido de las fuentes para construir el relato del santo, acorde a la sensibilidad espiritual y a las preferencias estéticas y literarias en boga en la Valencia de los albores de la Modernidad.

\section{La TRADUCCión CaSTELlana DE LA VIDA DE SANT VINCENTE FERRER De Miquel Peres}

El texto de Miquel Peres no parece que volviera a reeditarse en las décadas sucesivas, por lo que sorprende que, en 1589, precisamente en unos años en que se lleva a cabo la revisión y actualización de las compilaciones hagiográficas medievales y se consolida la llamada "hagiografía crítica" (Collins 133-36), se reeditase el texto de Peres, ahora traducido al castellano. De hecho, en la ciudad ya se había publicado pocos años antes, en 1575, la vida vicentina de Vicente Antist, que obedecía plenamente a los nuevos parámetros hagiográficos más rigurosos, como veremos más adelante.

La obra de Peres, pese a que partía de las fuentes oficiales, no cumplía los requisitos que la hagiografía moderna exigía: autoridades reputadas e historicidad contrastada. Ni Peres declaraba ninguna de sus fuentes, ni lo hacía en esta ocasión el traductor -quien, además, omitió incluso el nombre del autor valenciano, por lo que se editó como relato anónimo-. Hemos de considerar también la particular visión intimista que el autor valenciano mostraba del santo, alejada de la cada vez más consolidada imagen de san Vicente como predicador apocalíptico y hacedor de milagros. Y de hecho, aunque en el título de la portada de la traducción se indique que se imprime con licencia, esta no figura en las hojas preliminares, como era obligado en las vidas de santos publicadas en la segunda mitad de la centuria, tal vez, porque, como sugiere Canet (31), se trataba de un texto breve de naturaleza popular.

Tomás Martínez ha analizado las particularidades de esta traducción, que, por lo general, traduce fielmente el original. Sin embargo, hay algunas modificaciones puntuales que, en lo estilístico, atenúan la artificiosidad de la prosa (2012, 306-08), y en lo conceptual, afinan algunas afirmaciones teológicas que resultan poco atinadas en la nueva coyuntura religiosa postridentina (2012, 310-11). Sin embargo, los cambios más llamativos parecen responder a estrategias editoriales para potenciar el atractivo del librito: añadiendo nuevos milagros, haciendo cambios en su estructura o embelleciéndolo con nuevos grabados. Además del grabado del verso del primer folio, que reproduce más toscamente el que ya estaba presente en la obra de Peres (que muestra la icó- 
nica figura del santo señalando al cielo), se añaden otros dos nuevos para la portada y contraportada: san Vicente predicando desde el púlpito ante un público de variada condición social (fol. 1r), y una representación del juicio final (fol. 12v). Estos grabados, por tanto, representan la imagen de la santidad que se había consolidado del santo, como predicador de masas y portador de un mensaje apocalíptico, aunque esta última no es la imagen que se desprende de este relato.

En lo concerniente al texto, el primero de los cambios ya se insinúa en el título: "La vida de sant Vicente Ferrer con muchos milagros que obró, assí en su bienaventurada vida como después de su gloriosa muerte". Y efectivamente, la obra contiene muchos milagros, los dos capítulos que ya había incluido Peres, más uno nuevo ahora añadido al final, donde se narran "Algunos milagros que nuestro Señor obró por medio de este glorioso santo del año 1517”. Con esta rúbrica, de sensibilidad marcadamente postridentina, ya que se subraya la idea de que los santos son solo intercesores de la gracia, ${ }^{26}$ se incluyen una serie milagros acaecidos en tierras valencianas y datados todos ellos en las primeras décadas del siglo XVI. Para Martínez (2011a, 660), este añadido se justifica por la necesidad de rellenar los folios restantes del último cuaderno (ya que el texto de Peres solo ocupa 9 de los 12). ${ }^{27}$ Sin embargo, el editor $-\mathrm{y}$ probablemente refundidor-sabía del interés que despertaba este añadido que vinculaba el texto con la tradición local, por lo que quizá la operación no era ni tan irrelevante ni circunstancial, y por ello decidió incluso destacarlo en el título. Con este añadido, además, el responsable de la edición, quizá sin tener plena conciencia de ello, aunó las dos tradiciones devotas existentes sobre el santo en la ciudad: la proveniente de las vidas italianas oficiales y la local (Martínez 2011a, 664).

Esta relación de milagros locales debió de tener cierta circulación, porque también Vicente Antist recoge en su Vida y historia sobre san Vicente algunos de estos sucesos (cap. 37), y como demostró Martínez (2011a, 662), ambos textos debieron beber de esa fuente común, movidos por el deseo de recoger testimonios de prodigios obrados por el santo en su tierra natal. Estos

26. Esta manera de introducir los milagros, recordando que son obrados por Dios con la intercesión de los santos, será una fórmula habitual que usaran también los nuevos compiladores modernos, Villegas y Ribadeneira.

27. En el último folio (12r) también se añaden dos redondillas que compuso "en alabança del bienaventurado sanct Vicente [...] el impressor de su historia". El impresor, por tanto, se demuestra capaz de ejecutar algunas operaciones literarias, por lo que es fácil pensar que fuera él mismo el responsable, al menos, de las modificaciones y refundiciones del texto. 
milagros se narran con muchos detalles que confieren autenticidad a los relatos: lugar del prodigio, fecha, nombre y profesión de muchos de los protagonistas, etc. Sin duda la información que la sensibilidad crítica del Quinientos requería, y las instancias eclesiásticas exigían. ${ }^{28}$ Así, con la inclusión de estos relatos, no solo se acercaba la vida a la devoción local, sino también a una nueva manera de tratar la materia miraculística con mayor rigor:

El hijo del honrado Carlos especiero [...]. Esto aconteció a los veynte y uno de setiembre en el año de mil y quinientos y diez y siete. (Vida, fol. 10v)

A los seys de agosto en el año de mil y quinientos y veynte y siete, en un lugar que está a dos leguas de la ciudad de Valencia, dicho Raphel Buñol, havia un hombre llamado Matheo Muñoz, vezino dese dicho lugar. (Vida, fols. $10 \mathrm{v}-11 \mathrm{r}$ )

Jueves segundo día de Quaresma del año de 1519, Hieronymo Guitart de Gandía, principal ciudad (aunque pequeña) en el reyno de Valencia. (Vida, fol. 11v)

El segundo cambio significativo que muestra la edición castellana reside en la nueva disposición de los capítulos, ya que el que aparecía en séptimo lugar en el original, y que incluía la oración latina contra la peste a la que me he referido más arriba, aparece ahora el primero, precediendo a la narración estricta de la vida. ${ }^{29}$ Martínez (2011a, 656-59) ya explicó con acierto la oportunidad de esta estrategia editorial, pues aquel año, ante el brote de peste que afectaba a Cataluña, la ciudad de Valencia extremaba las precauciones para protegerse del contagio de la epidemia. Sin duda la oración antepuesta para ser "libres de aquel mal" serviría de reclamo para los devotos, ya que la fama del santo como protector del morbo ya estaba muy asentada.

Este cambio escasamente afecta a la estructura general del relato, porque si bien este apartado se aprovechaba en la obra original para representar el poder salvífico del dominico ante la peste, es decir, otro más de sus prodigios, se

28. Por lo general, ya las compilaciones de milagros reunidas hacia finales del siglo XV eran mucho más rigurosas en la anotación de estas informaciones. De hecho, en los centros de peregrinación, como el de Montserrat o el de Guadalupe, los relatos eran recogidos por notarios que daban fe de los hechos narrados y detallaban este tipo de datos (ver Díaz Tena).

29. También se ha eliminado la dedicatoria que Peres dirigía a doña Cirera d'Alpont, "muller del magnífich micer Pere d'Alpont, Regent la Cancelleria y del Consell del Rey", que parecería del todo obsoleta ocho décadas después, y por tanto, también se suprime la única referencia al autor que contenía el original (Martínez 2011a, 655). 
incluía apenas hilvanado con el resto de la historia con la pequeña narración que daba pie a la inclusión de la plegaria. Martínez (2011a, 657) ya señaló que en la traducción castellana se había suprimido dicha introducción, ese pequeño diálogo entre san Vicente y sus discípulos al que me he referido anteriormente, porque en este caso el remedio parece ser lo único que verdaderamente importa del apartado. Así, el refundidor sintetiza ese fragmento de la siguiente manera: "Estando este glorioso sancto en una ciudad que morían de pestilencia fue persuadido de algunos a que les diesse una oración, y él le dio la que sigue, con la qual (con el favor divino) serían libres de aquel mal" (Vida, fol. 2r). Sin embargo, nunca se ha comentado que en esta operación también se consigue otro objetivo probablemente de manera intencionada: el de purgar los elementos inconvenientes que pudieran inducir a un uso heterodoxo de la plegaria para presentarla conforme a la ortodoxia postridentina. En consecuencia, se han suprimido las alusiones a usos o rituales supersticiosos y las promesas vanas, o vanas observancias, presentes en la versión original; ${ }^{30} \mathrm{y}$ asimismo, en el nuevo enunciado se incide en la naturaleza divina del prodigio, recordando que tanto el santo, como la oración, son instrumentos a través de los cuales Dios concede la gracia.

Otro detalle poco notado es que, para aumentar el valor preventivo de la plegaria, flanqueando el grabado de la cruz que ya presentaba la versión original, se han incluido otros dos grabados más pequeños que representan a san Sebastián (otro célebre santo protector contra la peste) y a san Cristóbal (protector de la muerte súbita). Sin embargo, este añadido gráfico, que también parece responsabilidad del refundidor, vuelve a acercar implícitamente la oración a un uso como talismán de salvaguarda, al presentarse más efectiva por la sola inclusión de los grabados de los dos santos protectores. ${ }^{31}$

Por todos los elementos expuestos -la publicación de un libro devoto sin autoría expresa ni licencia, sin la declaración de fuentes reputadas; la inclusión de milagros locales, o la utilización de la plegaria como uno de sus atractivos-, parece evidente que se trata de un producto de naturaleza marcadamente popular, pese a las operaciones del refundidor por adecuarse al espíritu postridentino o, tal vez, para salvar en lo posible los recelos de la censura. Los herederos del taller de Joan Navarro, sabedores de la ferviente devoción por el

30. Para la caracterización y función de las vanas observancias de las oraciones, ver Londoño.

31. En Arronis (en prensa) se exponen otras consideraciones sobre este añadido gráfico, y sobre el uso y la difusión que tuvo esta plegaria en posteriores vidas del santo. 
santo en su tierra natal, apostaron por recuperar un manual antiguo que pudiera satisfacer ese interés, que difundía noticias de su vida y que permitía acopiar muchos milagros, probablemente para competir con otras vidas que debían de circular, destinadas a un público devoto que tal vez no tenía al alcance obras como la de Vicente Antist, de propósito más ambicioso y erudito, y que, probablemente, comportarían un coste económico mucho más elevado. Pero, pese a todo, este librito no debió de tener un gran éxito, ni se debieron de hacer más tiradas. Por un lado, el estilo literario artificioso que caracterizaba el original, aunque algo aligerado por el traductor, ya no se consideraría ni de moda, ni pertinente para la temática tratada. ${ }^{32} \mathrm{Y}$, por otro, la espiritualidad intimista que Peres había reflejado en sus páginas no conectaría con los anhelos del público de finales del Quinientos, ni se correspondería con la imagen consolidada ya del santo como predicador de masas y hacedor de milagros.

Mientras Peres, siguiendo su propósito, había modelado un san Vicente casi contemplativo, los nuevos relatos vicentinos que se difundían tras Trento subrayaban otros aspectos de su santidad, hasta entonces poco notados, y plenamente en sintonía con los valores que abanderaba la Iglesia de la Contrarreforma.

\section{LA VIDA Y HISTORIA DEL APOSTÓLICO PREDICADOR SANT VINCENTE FERRER DE ViCENTE Justiniano ANTIST}

La vida vicentina que publicó el también dominico Vicente Justiniano Antist (Valencia: Pedro de Huete, 1575) es la primera que obedece plenamente a los preceptos postridentinos sobre el tratamiento de la materia hagiográfica. ${ }^{33}$ Además, ya no depende solo de los relatos italianos considerados oficiales, sino que prepara una versión personal a partir de todas las fuentes autorizadas que se habían ocupado hasta la fecha del santo predicador -incluso obras de compiladores coetáneos, considerados autores graves, como Lorenzo Surio y Luis

32. La Inquisición también vigilaba que los escritos tocantes a la materia de la devoción o la fe tuviesen un estilo adecuado. Sobre la censura de lo malsonante ver Vega (147-48).

33. La vida de san Vicente no fue la única obra hagiográfica que escribió este dominico, aunque sí la primera; también preparó la de otros santos que debían ser de interés en la Valencia de la época, como Raimundo de Peñafort, San Pedro González Telmo, abogado de los navegantes, san Vicente Mártir, patrón de Valencia, una Relación de la vida y muerte del P. Fray Luis Bertrán, que se hizo muy popular, y que resultó ser un material clave para la canonización del que había sido su superior en el convento de Valencia, entre otras. 
Lippomano- y de toda la documentación de que dispone, entre la que incluye una copia del expediente del proceso. Toda esa información se cita convenientemente en el texto o en los márgenes, para identificar la procedencia exacta de las informaciones y demostrar la autenticidad del relato, ya que esta es una de las intenciones fundamentales del autor, tal y como lo expone en la epístola proemial que dirige a los Jurados de Valencia: ${ }^{34}$

De una sola cosa solamente creo que podrán v.s. estar satisfechos, que es de la verdad de la historia, en la qual he puesto gran diligencia; porque entiendo quan aborrecible es a Dios la mentira en todo caso, y mayormente en historias de sanctos [...]. Porque viendo los ignorantes las historias de algunos sanctos, compuestas por ciertos auctores, llenas de consejas, sospechan luego (aunque sin bastante razón) que tales deven de ser todas las otras, y assí pierden el crédito los autores verdaderos y recatados, por los fabulosos. (Antist, s.p.)

Estas declaraciones están en sintonía con el sentir general de los hagiógrafos que anhelaban la reforma de la materia, ya que la falta de crédito de algunas historias no solo hacía incurrir a los sencillos en errores y supercherías, sino que eran incluso motivo de burla y escarnio de los protestantes. ${ }^{35}$ Asimismo, las argumentaciones del "prólogo [...] al christiano lector", sobre el provecho de la lectura de las vidas de los santos y la necesidad de imitar sus obras, cobran pleno sentido como estrategia de difusión del posicionamiento católico en la controversia de la justificación por la fe y la necesidad de hacer buenas obras.

Pero el rigor con que se contrastan y ensartan los datos para construir una hagiografía crítica, no empece para que también en este caso la figura del santo se modele acorde al propósito del autor, y se le presente en sintonía con las ambiciones contrarreformistas. Junto a la vida ascética, la peregrinación itinerante, su faceta política, su don profético o su faceta taumatúrgica, ahora se enfatizan otros rasgos de su vida y personalidad, como la obediencia y el sometimiento a las autoridades eclesiásticas superiores; su anhelo por combatir las herejías de su tiempo con su tarea pastoral; el respeto y discreción con que criticaba a los religiosos en privado, o su cuidado en no predicar cuestiones su-

34. Incide de nuevo en este proceder crítico en el capítulo XL de la segunda parte, el último de la obra, en el que cita las principales fuentes y documentos que ha manejado.

35. Baños edita y traduce algunos de estos testimonios. 
tiles difícilmente comprensibles por el pueblo llano, algo que ya se había decretado en el Concilio: ${ }^{36}$

era tanta su humildad, que no quería predicar sin licencia de los Prelados y Obispos en cuyas diócesis se hallaba [...] y así es razón, que siempre les hagan vasallaje y les reconozcan superioridad. En lo qual no solamente les grangearán las voluntades, mas harán a Dios servicio, y no pequeño. (Antist 73-74)

En su predicación guardó esta reverencia a los clérigos y religiosos, que muy pocas vezes les reprehendió en público, particularmente de peccados que pudiesen escandalizar al pueblo, que antes no los sabía. (Antist 46) ${ }^{37}$

Como vemos, estas afirmaciones cobran una significación muy concreta a la luz del contexto de la respuesta del catolicismo a la ya consolidada berejía protestante, contra la cual la figura del santo emerge como un contraejemplo. Pero no deja de ser sorprendente que, precisamente, algunos de estos comportamientos que se le atribuyen no se corresponden con los que se deducen de sus predicaciones. Por ejemplo, son conocidas las severas críticas que el dominico dirigía públicamente a los prelados, a los que a menudo acusaba de simonía y concubinato en muchos de sus sermones, ${ }^{38}$ y es asimismo matizable la afirmación de que nunca predicó cuestiones teológicas sutiles, pues en muchas de sus exposiciones intenta hacer comprensible al público sencillo misterios como el de la Trinidad, la transustanciación, la predestinación o la resurrección de la carne. ${ }^{39}$

Cátedra (73) ya subrayó cómo Antist marcaba distancias con los sermones de Ferrer, especialmente con los que circulaban impresos en romance:

36. Al abordar la existencia del purgatorio en el Concilio, se concluyó que se excluyesen de los "sermones predicados en lengua vulgar a la ruda plebe, las cuestiones muy difíciles y sutiles que nada conducen a la edificación y con las que rara vez se aumenta la piedad" (López de Ayala 327). El propio Antist aplica este criterio en la obra, y en alguna ocasión en que aporta cartas en latín que tratan cuestiones elevadas argumenta: "No la he querido arromançar, porque los doctos ya la entendarán assí, y los simples no tienen grande necessidad de entenderla" (177-78).

37. Se condiseraba escandalosa toda afirmación o proposición que diera ocasión de caída o ruina espiritual a los que las leen u oyen, y estaba clasificada por la Inquisición como una de las censuras menores (ver Vega 145). Que el pueblo supiese de los vicios del clero podía escandalizarlos y alejarlos de la fe.

38. Ver ejemplos de las críticas a los clérigos y monjes en los sermones editados por Sanchis Sivera y Schib (I 257; III 18, 109-10).

39. Cátedra (606-07) edita un sermón que versa sobre la Resurrección y explica cómo será posible. Sobre la transustanciación, ver Sanchis/Schib (I 259) y sobre la predestinación (II 168). 
acerca de los sermones del Santo que andan impresos, es de saber que no los juntó él con intento de imprimirlos [...]. Tampoco los juntó para publicarlos ansí de mano. [...] Digo esto de los sermones que andan en latín, que unos seis o siete que unos años había imprimido no sé quién, no los tengo por suyos, por algunas buenas razones que no hay para qué escribirlas aquí. (Antist 61-62)

Sobre las razones que no declara, opina Cátedra (74) que se debía de tratar “de la desconfianza ante un tipo de textos poco aceptados por los revisionistas de la figura de san Vicente, en especial dentro de su orden". Toro recuerda que los sermones vicentinos que más difusión tuvieron en romance en la segunda mitad del XVI se ocupaban del fin del mundo y la llegada del Anticristo, y circularon de manera particular entre los alumbrados. ${ }^{40}$ Para Antist, pues, resultaba crucial alejar su texto de otras tradiciones menos ortodoxas para consolidar la imagen que proponía del santo valenciano.

La obra se divide en dos partes siguiendo el orden cronológico. De resultas, en la segunda parte solo seis capítulos se ocupan de los últimos tiempos de la vida del predicador en Bretaña, donde fallece, mientras que más de treinta se dedican a la narración de milagros post mortem atribuidos al santo. ${ }^{41}$ Antist quiere dar cabida a todos los prodigios que se le atribuyen, y su esfuerzo se ha centrado en ordenarlos por tipos de prodigios, siguiendo el ejemplo de las compilaciones de milagros modernas: ${ }^{42}$

"De los muertos que resucitó el glorioso San Vicente", "De los muchos que se vieron en peligro de muerte y San Vicente los libró", "De los ciegos que alumbró", "De los sordos y mudos que sanó", "De los que sanó de gota coral", "De los locos a quienes volvió el seso y de los endemoniados que limpió", "De las muchas mujeres preñadas a quienes libró de trabajo", "De los que tenían algunas partes del cuerpo fuera de lugar y San Vicente los sanó", "De los que sanó de calentura", "De los que sanó de enfermedades de brazos y piernas", "De los que libró de dolor de

40. Esta colección de Sermones de sant Vicente Ferrer en los quales avisa contra los engaños de los dos Antechristos y amonesta a todos los fieles christianos que estén aparejados para el fuycio Final se editaron un total de once veces entre 1550 y 1612 (Toro 521-22).

41. No obstante, Antist también se ocupa del proceso de canonización, e incluye un capítulo dedicado a narrar la vida del papa valenciano Calixto III, otro, al proceso iniciado por dicho papa y otro, a la bula de su canonización (422-50).

42. La edición de Díaz Tena sobre los milagros de Guadalupe permite ver cómo esta clasificación era la habitual. 
muelas", "De los que sanó del dolor del estómago y del vientre", "De los que sanó del mal de piedra o dificultad de echar la orina", "De algunos a quienes sanó de gota", "De los que libró de pestilencia", "De los que sanó de lepra", "De los que libró de veneno", "De las veces que fueron algunas personas o cosas libradas del fuego", "De los quebrados a quienes el Santo sanó", "De los que sanó de dolor de costado"...

El espacio que dedica en la obra a los milagros es reflejo de la importancia que concede a su faceta taumatúrgica, muy consolidada entre los fieles, por lo que su afán se centra en aportar legitimidad a los sucesos y dar pruebas de su autenticidad. Por ello, los reproduce con tantos -o tan pocos- datos históricos como debía de haber en las fuentes manejadas (principalmente las actas del proceso de canonización):

Rolando Bondic, marinero, estuvo siete años muy trabajado con un ahogamiento de pechos, que no podía ressollar sino con gran angustia [...] en el año de 1453 [...]. (Antist 415)

Una mujer que havia visto al sancto predicar en Dinanno, que está no muy lexos del obispado de Vannes, un año después de su muerte tuvo [...]. (Antist 418)

El mismo proceder aplica a la tradición devota local, y afirma que los milagros que incluye acaecidos en Valencia (cap. 37) son probados y dignos de fe, pues han sido tomados de un librillo que circulaba con la vida del santo que narraba milagros "hechos aquí en Valencia en tiempos de nuestros padres y abuelos", que juzga de "mucho crédito, porque van bien referidos y antes que se imprimiesen fueron examinados por personas que pudieron fácilmente comprobar su verdad" (Antist 454).

La vida de Antist, por tanto, se puede considerar la primera hagiografía crítica sobre el santo; alcanzó una gran difusión y aceptación, e influyó en las relaciones vicentinas posteriores, como la de Villegas y Ribadenira, que la citan con frecuencia, y en otras biografías del XVII (principalmente en la de Francisco Diago, que la toma como base). Sin embargo, también se mostró crédulo ante algunas tradiciones devotas locales, como hacerse eco de la supuesta aparición de Francina Ferrer a su hermano para relatarle que se encontraba en el purgatorio por haber muerto en pecado, y pedirle que intercediera por ella: "hallamos en memorias antiguas que, cantando él missa en el altar mayor de Predicadores, se le apareció ella, puesta en grandes tormentos 
del purgatorio y le rogó que se apiadasse della" (Antist 296). Esta creencia popular ya debía existir en el siglo XV y dio origen a las llamadas misas de san Vicente por las almas del purgatorio (Martínez 2011b, 5). Como vemos, Antist no precisa la fuente de este episodio, pero le da crédito por el peso de la tradición, que toma como un elemento de legitimación.

Pese al rigor del que hace bandera, y la buena acogida del texto, pronto otras hagiografías consideraron insuficiente el manual de Antist, y nuevas obras fueron completando la biografía vicentina, aunque profundizando en la línea inaugurada por este dominico. ${ }^{43}$

\section{CONCLUSIONES}

El recorrido expuesto sobre estas vidas ha permitido comprobar cómo, en diferente medida, todos los autores se sirven de la polifacética figura del santo para modelar la narración de su vida acorde al objetivo concreto que persiguen: ejemplificar el espíritu de la orden dominica, enfatizar el recogimiento contemplativo, ponderar la humildad, obediencia y discreción, fascinar con la faceta taumatúrgica, difundir una salvaguarda ante el contagio de peste, etc. Para ello, en ocasiones ha bastado con destacar unos episodios sobre otros, que se obvian o se resumen; en otras, los hagiógrafos han modelado los hechos más libremente. El ejemplo de Peres sería el más destacado en este sentido, pero las intervenciones -aunque sutiles- sobre el relato de la vida para ponderar una u otra imagen del santo, las vemos en casi todos los textos. Incluso hagiógrafos postridentinos, como Antist, que prodiga la historicidad de su tratado, hicieron lo propio para perfilar la santidad del dominico acorde a un modelo que encarnara los preceptos católicos y las necesidades que exigía la Iglesia contrarreformista.

El hecho de que todas las vidas tengan en cuenta unas mismas fuentes -en exclusiva o no-, relativamente cercanas en el tiempo, hace que no haya divergencias importantes en el contenido de las narraciones, por lo que se hace más patente que las operaciones de los hagiógrafos son deliberadas.

43. Los autores del XVIII, como Serafín Tomás Miguel, Francisco Vidal y Micó o José Teixidor, prefirieron basarse ya directamente en la obra de Diago (Robles, xxii-xxiii), que completaba y superaba en rigor histórico la de Antist. Para Sanchis Sivera, la obra de Antist presenta "muchas inexactitudes en la cronología, la narración resulta muy pesada y carece completamente de plan", y precisamente explicita que además de sus fuentes, también tuvo en cuenta "las tradiciones que en su tiempo existían" (Sanchis Sivera, xi). 
De modo que, en lo que respecta a la hagiografía anterior y posterior a Trento, la realidad no es tan simple como a priori pudiese pensarse, ni siquiera en el tratamiento de lo sobrenatural. La principal diferencia que se percibe es la mayor preocupación de los postridentinos a la hora de afirmar la autoridad de las fuentes, que estas estén contrastadas con los hechos históricos o provengan de autores reputados -autores graves, en terminología de la época-; es decir, un mayor rigor metodológico en el tratamiento de la información. Asimismo, los autores son plenamente conscientes de la misión que han de acometer con sus escritos, y así lo exponen en los prólogos y paratextos, que aprovechan para declarar explícitamente el sometimiento a la censura de la Iglesia en virtud de la ortodoxia de la devoción, y para ensalzar la ejemplaridad de los santos y los beneficios de imitarlos.

\section{OBRAS CITADAS}

Albisson, Mathilde. "La censura de la literatura hagiográfica en lengua vulgar del Índice de Valdés (1559) al Índice de Zapata (1632)”. Rilce 36.2 (2020): 453-76.

Antist, Vicente Justiniano. La vida y historia del apostólico predicador sant Vicente Ferrer. Valencia: Pedro de Huete, 1575.

Aragüés Aldaz, José. "Los flores sanctorum medievales y renacentistas: brevísimo panorama crítico". Literatura medieval y renacentista en España: líneas $y$ pautas. Ed. Emilio Blanco. Salamanca: La SEMYR, 2012. 349-61.

Arronis Llopis, Carme. La vida de la sacratíssima verge Maria de Miquel Peres (1494). Alicante: IIFV/Barcelona: Publicacions de l'Abadia de Montserrat, 2015.

Arronis Llopis, Carme. "Lecturas devotas y prohibiciones inquisitoriales: el caso de las Vidas de María". Christ, Mary and the Saints: Reading Religious Subjects in Medieval and Renaissance Spain. Eds. Andrew Beresford y Lesley Twomey. Brill: Leiden/Boston, 2018. 268-86.

Arronis Llopis, Carme. "El Tractado de la vida de Christo: sobre prohibiciones «hagiográficas» del Índice de Fernando de Valdés (1559)". Hispania Sacra 71.144 (2019): 481-92.

Arronis Llopis, Carme. "Superstition and Faith: The Prayer against the Plague Attributed to Saint Vincent Ferrer" (en prensa).

Baños Vallejo, Fernando. "Lutero sobre la hagiografía y los hagiógrafos sobre Lutero”. Studia Aurea 13 (2019): 7-40. 
Calvé Mascarell, Óscar. La configuración de la imagen de san Vicente Ferrer en el siglo XV. 2016. Universitat de València: tesis doctoral inédita. 18 de abril de 2019. <http://roderic.uv.es/handle/10550/54943>.

Càmara Sempere, Hèctor. El Flos Sanctorum Romançat: edició crítica dels dos incunables catalans de la Legenda aurea de facobus de Voragine. 2013. Universitat d'Alacant, tesis doctoral inédita. 18 de abril de 2019. <http://hdl. handle.net/10045/74851>.

Canet, José Luis. "Hagiografía valenciana (1470-1600)". Les Cahiers de FRAMESPA: Nouveaux Champs de l'Histoire Sociale 1 (2005). 28 de diciembre de 2019. <https://journals.openedition.org/framespa/411>.

Cátedra García, Pedro. Sermón, sociedad y literatura en la Edad Media: san Vicente Ferrer en Castilla (1411-1412). Salamanca: Junta de Castilla y León, 1994.

Collins, David J. Reforming Saints. Saints' Lives and Their Authors in Germany, 1470-1530. New York: Oxford UP, 2008.

Díaz Tena, M. ${ }^{a}$ Eugenia. Los milagros de Nuestra Señora de Guadalupe (siglo XV $y$ primordio del XVI). Mérida: Editora Regional de Extremadura, 2017.

Eiras Roel, Antonio. "Demografía rural en la España moderna: evolución, variantes y problemas". El mundo rural en la España moderna. Ed. Francisco J. Aranda Pérez. Cuenca: Universidad de Castilla la Mancha, 2004. 19-76. Ferrando Francés, Antoni. Sant Vicent Ferrer en la bistoriografia, la literatura, l'hagiografia i l'espiritualitat al segle XV. València: Alfons el Magnànim, 2013. Ferrer de Valdecebro, Andrés. Historia de la vida maravillosa y admirable del segundo Pablo apóstol de Valencia, san Vicente Ferrer. Madrid: Mateo de Llanos, 1682.

Huijbers, Anne. "De viris illustribus ordinis praedicatorum: A «classical» genre in Dominican hands". Franciscan Studies 71 (2013): 297-324.

La vida de sant Vicente Ferrer con muchos milagros que obró. Valencia: Herederos de Joan Navarro, 1589.

Londoño, Marcela. "Cosas vanas, curiosas y supersticiosas: la censura de los Libros de Horas en los Índices de España y Portugal”. Saberes inestables: estudios sobre expurgación y censura en la España de los siglos ХVI y ХVII. Eds. Víctor Lillo, Dámaris Montes y M. ${ }^{a}$ José Vega. Madrid: Iberoamerica/ Frankfurt am Main: Vervuert, 2018. 25-74.

López de Ayala, Ignacio, ed. y trad. El sacrosanto y ecuménico Concilio de Trento. Barcelona: Ramón Martín Indar, 1847.

Martínez Romero, Tomàs. "Sobre les causes i les estratègies editorials d'una traducció: La vida de sant Vicente Ferrer (1589)". Bulletin of Spanish Studies 88.5 (2011a): 655-65. 
Martínez Romero, Tomàs. "La hermana de San Vicente Ferrer en el Purgatorio: un tema medieval en la literatura barroca". Rassegna iberistica 94 (2011b): 3-12.

Martínez Romero, Tomàs. "De La vida de Sant Vicent, de Miquel Péreç, a la Vida castellana". Literatures ibèriques medievals comparades. Ed. Rafael Alemany. Alacant: Universitat d'Alacant, 2012. 303-12.

Martínez Romero, Tomàs. Bernat Fenollar i Miquel Estela, poetes de cançoner. València: Tres i Quatre, 2018.

Pérez García, Rafael. "Del uso mágico de lo escrito en el siglo XVI". Actas del III Congreso de Historia de Andalucía: Historia Moderna. Vol. 3. Córdoba: Cajasur, 2003. 251-66.

Ribadeneira, Pedro de. Vidas de santos que comúnmente llaman extravagantes porque la santa Yglesia no reza dellos en el Breviario Romano. Madrid: Luis Sánchez, 1604.

Robles Sierra, Adolfo. "Algunos problemas que plantea la historiografía de San Vicente”. José Teixidor. Vida de San Vicente Ferrer, apóstol de Europa. Ed. Alfonso Esponera. València: Ajuntament de València, 1999. xiii-xxviii.

Sanchis Sivera, Josep. Historia de san Vicente Ferrer. Valencia: Sucesores de Badal, 1896.

Sanchis Sivera, Josep, y Gret Schib, eds. Sant Vicent Ferrer. Sermons. 6 vols. Barcelona: Barcino, 1932-1988.

Smoller, Laura Ackerman. The Saint and the Chopped-Up Baby: The Cult of Vincent Ferrer in Medieval and Early Modern Europe. Ithaca, NY: Cornell UP, 2014.

Toro Pascua, María Isabel. "Literatura popular religiosa en el siglo XVI: los sermones impresos de San Vicente Ferrer". Studia aurea: actas del III Congreso de la AISO (Toulouse, 1993). Vol. 3. Eds. Ignacio Arellano y otros. Pamplona: GRISO, 1996. 521-30.

Vauchez, André. Sainthood in the Later Middle Ages. Cambridge: Cambridge UP, 2017.

Vega Ramos, María José. "Escandaloso, ofensivo y malsonante: censura y vigilancia de la prosa espiritual en la España del Siglo de Oro". Criticón 120-21 (2014): 137-54.

Wittlin, Curt. "Sobre les vides de sant Vicent Ferrer compilades per Ranzano, Antonino i Miquel Peres, amb una edició de la Vita sanctii Vincentii Ferrerii, de Francesco de Castiglione". Anuari de l'Agrupació Borrianenca de Cultura 5 (1994): 5-27. 